\section{A Cholecystocolic Fistula Demonstrated by Endoscopic Retrograde Cholangiopancreatography}

P. Schoeters, H. Fierens, L. Colemont,

E. Van Moer

Division of Gastroenterology,

Sint Vincentius General Hospital,

Antwerp, Belgium

\section{Corresponding Author}

\section{P. Schoeters, M.D.}

Division of Gastroenterology and Hepatology

University Hospital of Antwerp

Wilrijkstraat 10

2650 Edegem

Belgium

Fax: $\quad+32-3-8254678$

E-mail: patrick.schoeters@uza.be

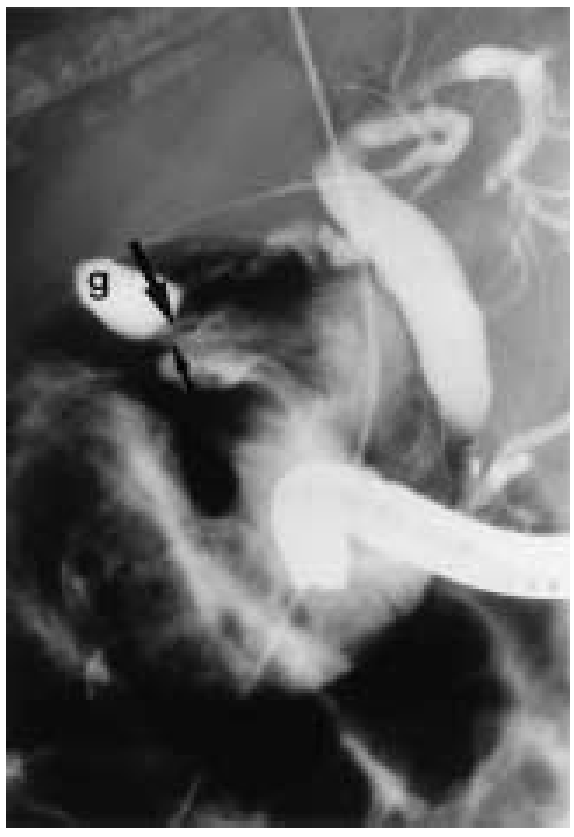

Figure 1 An 81-year-old woman, without any relevant medical history, underwent endoscopic retrograde cholangiopancreatography (ERCP) because of incidental pneumobilia discovered on plain abdominal radiography and ultrasound. She had only minimal right upper abdominal complaints, without the typical clinical features of gallbladder diseases. Clinical and blood examination revealed no abnormalities. The ERCP showed the pancreatic duct and biliary tree to have a normal caliber. After the biliary tree was filled, a fistulous tract from the gallbladder to the right colon at the level of the hepatic flexure was visualized. Arrow, fistulous tract; $\mathrm{G}$, gallbladder

Figure 2 Visualization of the hepatic flexure

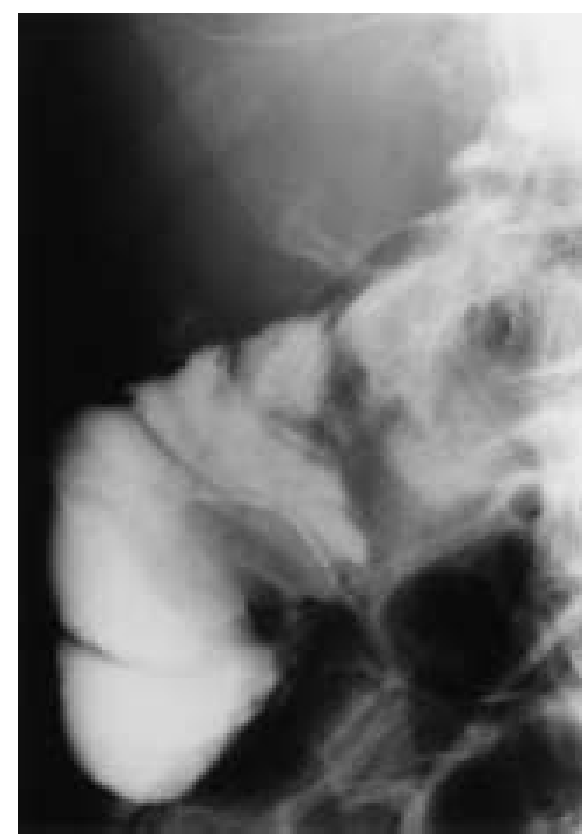
shortly after the biliary tree had been filled with contrast 